\title{
Os coletivos em cena: algumas contribuições para o debate
}

\author{
Collectives on the scene: some contributions to debate
}

Los colectivos en escena: algunas contribuciones

para el debate

Recebido em 14-06-2020

Modificado em 15-07-2020

Aceito para publicação em 23-08-2020

\section{doi) https://doi.org/10.47456/simbitica.v7i3.33691}

\section{Marcelo de Souza Marques}

Orcid: 0000-0003-2395-0191

Cientista Social pela Universidade Federal do Espírito Santo (UFES). Mestre em Ciência Política pela Universidade Federal de Pelotas (UFPel). Atualmente, cursa o Doutorado em Sociologia pela Universidade Federal do Rio Grande do Sul (UFRGS), onde integra o Grupo de Pesquisa Associativismo, Contestação e Engajamento (GPACE). Bolsista CNPq. E-mail: marcelo.marques.cso@gmail.com

\section{Vanessa Marx (iD}

Orcid: 0000-0002-3595-2883

Professora do Programa de Pós-Graduação em Sociologia e do Departamento de Sociologia da Universidade Federal do Rio Grande do Sul (UFRGS). Doutorado em Ciência Política e Administração - Universidad Autonoma de Barcelona (2008), reconhecido no Brasil pela USP. Coordenadora do Grupo de Pesquisa Sociologia Urbana e Internacionalização das Cidades (GPSUIC). E-mail: vanessa.marx@ufrgs.br

\section{Resumo}

Em meio ao recente ciclo de protestos pelo qual passou o Brasil entre os anos de 2013 e 2016, uma nova atenção teórico-analítica foi conferida às experiências organizacionais, que se autodenominam coletivos. Visando contribuir com esse debate, neste artigo, parte de uma pesquisa em andamento, nos guiaremos a partir de dois objetivos: (i) sistematização dos elementos centrais da recente literatura sobre coletivos que poderiam auxiliar um exame mais detido sobre essas experiências organizacionais; (ii) análise discursiva do processo de identificação dos sujeitos como coletivos contemporâneos. Para o segundo objetivo, também nos valemos de seis entrevistas realizadas com ativistas de coletivos culturais na Cidade de Vitória, Espírito Santo, entre os meses de dezembro de 2018 e março de 2019. Considerando os achados da literatura e nossos primeiros dados de pesquisa, o argumento estruturante da análise é que a construção da ideia de coletivo também significa a demarcação de uma posição diferencial em relação a outras experiências associativas.

Palavras-chave: Coletivos; posição diferencial; novas experiências associativas; repertórios.

\footnotetext{
* Este artigo é parte da pesquisa de doutorado em andamento. A pesquisa conta com o financiamento do Conselho Nacional de Desenvolvimento Científico e Tecnológico $(\mathrm{CNPq})$. Agradecemos a Adriano Monteiro e à Sabrina Cavassani, ativistas de coletivos culturais, pelas constantes trocas e momentos de aprendizagem. 


\section{Introdução}

Em meio ao recente ciclo de protestos que marcou o período de 2013 a 2016, o Brasil percebeu a emergência de diferentes experiências organizacionais e de mobilização que se autodenominam coletivos. Esse período evidenciou não apenas novas estratégias, performances e repertórios, como, igualmente, novos significados ao debate políticoorganizacional estruturados em torno de um discurso que podemos compreender como uma “crítica à política tradicional".

$\mathrm{Na}$ estruturação desse discurso, podemos identificar a crítica aos espaços e aos mecanismos tradicionais de participação e representação política (Borelli et. al., 2010), bem como a certos repertórios organizacionais e de ação de estruturas históricas ${ }^{1}$, como partidos políticos, sindicatos e mesmo certas organizações de movimentos sociais, tomados por muitos ativistas de coletivos como estruturas rígidas, formalizadas, hierarquizadas e centradas na ideia de "liderança" (Gohn, 2019). Essa crítica, no entanto, não parece se limitar ao cenário brasileiro - nem ao período de 2013 e 2016 -; trata-se de um fenômeno mais abrangente e com reflexos em diferentes contextos.

Como têm destacado Borelli et. al. (2010) e Gohn (2019), a estruturação desse contexto envolve a emergência de novos espaços de representação e participação política da juventude, como a experiência do Fórum Social Mundial, as paradas e marchas já verificadas no final dos anos 1990, como a Parada do Orgulho LGBT e a Marcha da Maconha, e, a partir dos primeiros anos da década de 2010, as ondas globais de protestos e ocupações, como a Primavera Árabe, as diferentes ações chanceladas pelo significante Occupy, os Indignados, na Espanha, os protestos em países como Portugal, Grécia, e, mais recentemente, em Hong Kong e Chile. Entre outras críticas e reivindicações trazidas à tona nesses contextos, tais como o combate à corrupção, a crítica ao desenvolvimento econômico sem garantias de proteção ambiental, a luta contra regimes autoritários, a busca por justiça social e racial, a luta pelo direito à cidade, dentre outas demandas e bandeiras, uma característica presente em todas elas seria a busca por novos repertórios organizacionais e de ação a partir de um discurso crítico às estruturas e organizações políticas percebidas como "tradicionais".

\footnotetext{
${ }^{1}$ Repertórios são padrões culturais e estruturais de organização e ação socialmente construídos e que, estando disponíveis aos sujeitos, são mobilizados em diferentes momentos históricos e por diferentes sujeitos coletivos na organização e ação política (Tarrow, 2009; Tilly; Tarrow, 2015). A partir desse conceito, Clemens (2010: 165) destaca a ideia de repertório organizacional, concebido como um "conjunto de modelos organizacionais cultural e empiricamente disponíveis" aos sujeitos coletivos. Trata-se, segundo a autora, de um conceito que “integra o vocabulário teórico dos estudiosos de organização sensíveis à diversidade de forma com o arcabouço cognitivo ou cultural dos 'repertórios de ação coletiva' postos em evidência pelos teóricos do movimento social sintonizados com a variação histórica".
} 
Tomando essa crítica como parte das condições estruturais de emergência de novas experiências associativas, bem como o atual debate sobre os coletivos contemporâneos no Brasil, temos como objetivos neste artigo (i) sistematizar os elementos centrais da recente literatura sobre coletivos que podem auxiliar um exame mais detido sobre essas experiências organizacionais e (ii) analisar o processo de identificação discursiva dos sujeitos como coletivos contemporâneos.

O uso do termo "coletivos contemporâneos" se justifica porque, como destaca Perez (2019:587), assim como a nomenclatura coletivos não é nova, ou seja, o termo já era utilizado em outros contextos e momentos históricos, também não são necessariamente novas as organizações que, recentemente, passaram a se intitular como tal ${ }^{2}$. Corroborando Perez, temos percebido que estamos diante de um processo de retomada do termo e de ressignificações de repertórios em um contexto estratégico-relacional situado - este é um dos temas que temos discutido em nossa pesquisa sobre os coletivos culturais. Os dados de pesquisa obtidos até o momento têm indicado que se trata de uma experiência que encontra suas primeiras emergências já com o movimento modernista, passando novas configurações relacionais nos anos 1960-1970 (contexto de ditadura militar), depois nos anos 1980-1990, em um novo contexto estratégico-relacional (redemocratização e novas experiências institucionais participativas) e nos anos 2000, com as novas políticas públicas culturais implementadas ao longo do governo petista, sobretudo entre os anos de 2002 a 2010 (Cf. Pirez, 2017; Paim, 2009; Rezende; Scovino, 2010; Rosas, 2005). Nesse sentido, quando nos referimos a coletivos contemporâneos, estamos a destacar aos coletivos dos anos 2000.

Com relação ao nosso primeiro objetivo, como destacaremos na primeira seção do artigo, buscamos sintetizar diferentes contribuições de estudos empíricos que, em alguma medida, apresentam discussões conceituais sobre as experiências de diferentes tipos de coletivos. Inicialmente realizamos uma pesquisa no SciELO. Diante dos poucos resultados, passamos a consultar o Google Scholar e os anais de encontro da Associação Nacional de Pós-Graduação em Ciências Sociais (ANPOCS) e da Sociedade Brasileira de Sociologia (SBS), realizados em 2017 e 2018 respectivamente. A partir da análise dos trabalhos encontrados, percebemos três eixos analítico-descritivos na literatura sobre os coletivos, a saber: dimensão organizacional, demandas ou projetos políticos e estratégias de mobilização e ação dos coletivos.

\footnotetext{
2 Também temos percebido algo semelhante no contexto capixaba. Alguns sindicatos de artistas, criados nos anos 1980, bem como alguns grupos profissionais da dança, teatro, dentre outros, na última década passaram a se reconhecer e a se autodenominar como coletivos. Nesse processo, até onde pudemos acompanhar, os sujeitos têm buscado novas formas de organização e de tomadas de decisões, no sentido de buscar maior horizontalidade.
} 
Em relação ao segundo objetivo, além da revisão de literatura, também nos valemos de seis entrevistas com ativistas de coletivos culturais no Espírito Santo, realizadas entre os meses de dezembro de 2018 e de março de 2019. Foi a partir da análise das entrevistas e da reflexão sobre os achados da literatura, que percebemos elementos que nos levaram a refletir sobre a estruturação discursiva dos sujeitos de uma posição diferencial na construção de sua própria experiência. A ideia de posição diferencial, aqui mobilizada para refletir sobre o processo de identificação dos sujeitos como (i) pertencente a um coletivo e (ii) ativista de coletivo, indica que não existe uma posição identitária clara, própria, autorreferente. A posição diferencial evidencia que todo processo de identificação também depende de uma correspondência que, ao mesmo tempo em que a excede, a constitui, destacando a necessidade de uma relação com um elemento externo para a constituição da "unidade interna" - esta já não está em termos de uma "unidade em si" (Staten, 1984; Laclau; Mouffe, 2015; Hall, 2000; 2011). Como discutiremos na segunda seção do artigo, ao se identificarem como coletivos e como ativistas de coletivos, os sujeitos mobilizam diferentes significados na demarcação de fronteiras conceituais em relação a outras formas de mobilização, organização e ação da sociedade civil contemporânea, tais como ONG's, partidos, organizações de movimentos sociais mais estruturadas do ponto de vista organizacional e da liderança, dentre outras. Nesse processo, os ativistas buscam evidenciar que os coletivos, ao contrário de outros tipos organizacionais da sociedade civil, são experiências caracterizadas por um menor grau de formalização, destituídas de hierarquia e liderança formal/vertical, pautadas na horizontalidade e no trabalho colaborativo, dentre outras características distintivas.

Não queremos dizer, com isso, que não existam novidades de fato nos repertórios organizacionais e na ação dos coletivos. Percebemos a "novidade dos coletivos" não como um fenômeno cuja experiência objetual se explica per se, e sim como uma experiência histórica radicalmente não-absolutizada. Isso significa a assunção da novidade enquanto um fenômeno situado nas e a partir das relações com os demais fenômenos no mundo. Desta forma, compreendemos que a percepção da novidade dos coletivos deve ser localizada na e a partir da construção discursiva de uma posição diferencial em relação a outras formas organizacionais de estruturas sociais coletivas contemporâneas presentes em nossa sociedade, tais como os partidos políticos, sindicatos, ONG's, organizações de movimentos sociais, associações profissionais, dentre outras.

Justamente por isso, iniciaremos a reflexão buscando compreender a estrutura organizacional dos coletivos, destacando os três eixos analítico-descritivos fundantes que localizamos no atual debate sobre os coletivos: dimensão organizacional, demandas elou 
projetos políticos e estratégias de mobilização e de ação. Na segunda seção do artigo, além da revisão de literatura, trabalharemos a partir de alguns dos dados que obtivemos até o presente momento da nossa pesquisa sobre os coletivos culturais no Espírito Santo. Para finalizar, buscamos estruturar as considerações finais de forma mais aberta, refletindo sobre a pertinência de pensarmos os coletivos como uma categoria analítica especial.

\section{Eixos analítico-descritivos na literatura sobre os coletivos}

Como toda novidade, a literatura sobre os coletivos se apresenta como um esforço em construção. No atual estágio do debate, há enfoques que percebem os coletivos como organizações inerentes à juventude contemporânea (Maia, 2013; Borelli; Aboboreira, 2011; Gohn, 2014; 2019), como uma interface entre movimentos juvenis e as crises representativas no interior do movimento estudantil (Mesquita, 2008), já outros, compreendem os coletivos como um fenômeno relacionado ao surgimento de uma nova configuração militante cuja origem está diretamente relacionada ao ciclo de protestos inaugurados a partir de 2013 (Lima; Schmitz, 2017; Andrade, 2017; Lima, 2018).

Pensamos que seria importante para a compreensão e o aprofundamento do tema, sintetizarmos um conjunto de elementos teórico-descritivos presentes nos trabalhos acima referidos e em outras importantes contribuições ao debate, para refletirmos sobre os coletivos em geral, tais como Bordt (1997), em seu estudo sobre os coletivos feministas nos Estados Unidos, Rosas (2004; 2005), em suas reflexões sobre os coletivos culturais no Brasil, Paim (2009), em sua pesquisa sobre os modos de fazer de coletivos e iniciativas coletivas do campo artístico-cultural na América Latina, Desouza (2012), na análise de coletivos de mulheres na Índia, Assis (2018) e Andrade (2017), sobre os coletivos de comunicação, Lima (2018), sobre os grupos e coletivos em torno do Encontro Nacional Universitário da Diversidade Sexual (ENUDS), e Perez e Silva Filho (2017), em estudo que lança algumas problematizações à literatura sobre os coletivos.

A partir da análise dessa literatura e de nossas entrevistas, percebemos certo nível consensual entre analistas e ativistas em torno do argumento de que os coletivos representam novas formas de mobilização, organização e ação da sociedade civil contemporânea, apresentando, portanto, certas “características próprias" quando comparados a outros agentes societários.

Essas características, quando apontadas pelos analistas para a dimensão organizacional dos coletivos, indicam se tratar de grupos menos estruturados em termos burocráticos e 
institucionais (Gohn, 2017; Lima, 2018; Perez; Silva Filho, 2017). Diferentemente de outras formas de organização e de ativismo, como setoriais partidárias, organizações de movimentos sociais, ONG's, sindicatos etc., os coletivos não apresentam, comumente, divisão interna entre secretariados, assessorias e lideranças, caracterizando-se, assim, por uma menor divisão interna do trabalho e um menor nível de formalidade. Ademais, também não apresentam uma "base social” coesa (Gohn, 2017). Ao contrário do que ocorre normalmente nos sindicatos e organizações de movimentos sociais, os laços entre os indivíduos e os coletivos, quando pensados para além das relações entre os ativistas, são mais fluidos, estruturam-se por meio de "apoiadores" que podem estar mais ou menos próximos em determinados contextos de mobilização e ação dos coletivos. Ou seja, os coletivos não possuem uma "base social" militante nos mesmos termos que outras experiências de ativismo.

Também nesse sentido, Maia (2013), Desouza (2012) e Lima (2018) destacam que a ausência de uma estrutura interna mais rígida nas experiências organizacionais dos coletivos reflete o esforço da construção cotidiana de uma lógica organizacional e de socialização baseada no compartilhamento de ideias entre os ativistas, nos laços afetivos ${ }^{3}$, no trabalho colaborativo, no princípio da autonomia da ação, na recusa da ideia de representação (formal) e de delegação (vertical). Algo que, discursivamente para os ativistas, seria uma dificuldade em outras experiências organizacionais (Perez, 2019). O objetivo dos ativistas, como destacado por essa literatura, é, portanto, a construção de uma estrutura comum, coletiva, destituída de hierarquia e de uma figura central de liderança, comum a determinadas experiências político-organizacionais, como os partidos políticos, sindicatos e certas organizações de movimentos sociais.

Esses elementos são constantemente ressaltados no exercício descritivo-conceitual sobre os coletivos, sobretudo quando analistas e ativistas buscam realçar as distinções em relação a outras formas associativas e de ação política no atual contexto nacional. Em um contexto de crítica à "política tradicional", esta distinção ocorre porque, como veremos na próxima seção, os ativistas, por um lado, percebem comumente as organizações de movimentos sociais e as ONG's como estruturas organizacionais estáticas, partidárias e hierarquizadas, e, por outro, autoconstroem a imagem dos coletivos como espaços dinâmicos, como mecanismos cotidianos de ação política pautados na autonomia e na horizontalidade.

Já quando eles remetem às demandas ou projetos políticos, as "características próprias”, destacadas pela literatura, indicam que os coletivos são mais pontuais e contextuais,

\footnotetext{
${ }^{3}$ Para uma análise aos afetos na análise dos coletivos, conferir Andrade (2017), Desouza (2012) e Paim (2009).
} 
conferindo maior flexibilidade política e organizacional. Essa flexibilidade imprime nos coletivos um caráter sempre aberto e descentrado do ponto de vista das demandas e dos projetos políticos (Maia, 2013; Lima, 2018; Paim, 2008).

Para a literatura, as ações políticas dos coletivos, diferentemente das organizações de movimentos sociais, por exemplo, não se baseiam necessariamente em ações estrategicamente orientadas por uma agenda ou um projeto político mais estrutural, e sim por demandas contextuais e constantemente articuladas (Gohn, 2017). Isso, contudo, não significa que os coletivos não possuem demandas ou projetos políticos, como se fossem ações momentâneas, puramente circunstanciais ${ }^{4}$.

Ao contrário do argumento de ausência, o que as análises da ação e da construção de agendas dos coletivos têm apontando é o caráter interseccional aparentemente inerente a essas organizações (Paim, 2009; Perez; Souza, 2017; Maia, 2013). Isso nos ajuda a compreender, por exemplo, tanto a existência de coletivos pautados por agendas múltiplas, como coletivos feministas negros, coletivos culturais feministas etc., como as múltiplas articulações dos coletivos, que vão deste as setoriais partidárias, passando por ONG's e diferentes bandeiras e organizações de movimentos sociais (Perez; Souza, 2017; Maia, 2013; Lima, 2018; Lima; Schmitz, 2017).

Os estudos de casos empíricos, portanto, têm demostrado que os argumentos que tendem a afirmar que os coletivos recusam relações com partidos, governos e mesmo com movimentos sociais, não se sustentam. Ainda que existam claras críticas aos partidos políticos, ao Estado e a outras instituições na ação e organização dos coletivos, isso não significa que estes rechaçam toda e qualquer forma de mediação política, tampouco significa que sua atuação necessariamente ocorre "fora das vias institucionais tradicionais" (Vommaro apud Perez, 2019:583). Como temos percebido em diferentes estudos empíricos recentes e também a partir de nossas atividades de pesquisa de campo, a ideia de que os coletivos recusam qualquer tipo de relação com a esfera institucional não deve ser tomada como uma dimensão analítica na compreensão das recentes experiências coletivas no contexto nacional, mas analisadas em suas manifestações particulares.

Por fim, no que diz respeito às estratégias de mobilização e ação dos coletivos, a internet, mais centralmente os processos de mobilização e articulação por meio de redes sociais online e das novas tecnologias de comunicação cada vez mais comuns no dia a dia dos sujeitos, se destaca nas análises e reflexões da literatura como um elemento inerente aos

\footnotetext{
${ }^{4}$ Para uma leitura que identifica, nos discursos dos próprios ativistas, o argumento de ausência de uma agenda política e as implicações disto, conferir Lima (2018).
} 
coletivos e, às vezes, é compreendida como um traço fundamental na distinção em relação aos movimentos sociais (Maia, 2013; Gohn, 2017; 2019).

Ainda que não evidenciado e/ou problematizado, o eixo analítico central nessa discussão na literatura especializada é a assunção do argumento de que os coletivos, assim como outras experiências coletivas contemporâneas, como os Indiganados e o Occupy, são fenômenos emergentes inerentes às "sociedades informatizadas" em que os sujeitos, conectados por meio das novas tecnologias de comunicação, passam a compartilhar ideais comuns e elaboram processos de mobilização e de ação sem a mediação das organizações, sejam de movimentos sociais, partidárias, sindicais, etc., configurando não mais em uma ação coletiva, mas em um tipo de ação próxima à ideia de "ação conectiva" (Bennett; Segerberg, 2012) $)^{5}$. Aqui precisamos fazer algumas observações de caráter crítico que não serão exploradas na próxima seção.

Certamente, como destacam Gohn (2017; 2019) e Andrade (2017), as novas experiências organizacionais e de ação da sociedade civil, emergidas nos últimos vinte anos no Brasil, se valem mais da internet e das tecnologias de comunicação do que qualquer outra organização social, fazendo dela seu principal canal de comunicação no processo de mobilização dos ativistas e apoiadores, na divulgação das campanhas de protestos, e na disputa pelo enquadramento social. Entretanto, talvez seja cedo para afirmarmos que, em países como o Brasil, ainda com consideráveis deficiências no acesso à internet e com uma forte desigualdade social ${ }^{6}$, estejamos vivenciando uma era de "democracia digital". Tampouco podemos dizer que hoje a internet e suas tecnologias, a despeito do uso crescente de smartphones e serviços onlines diversos, tenham promovido uma nova cultura social,

\footnotetext{
${ }^{5}$ Como destacam Bennett e Segerberg (2012:743), a ação conectiva, mais do que uma ideia de processos de estruturação da mobilização e da ação por meios de redes sociais online como recursos mobilizados pelos sujeitos, indica uma forma especial de ação pautada em novos padrões de comunicação personalizada e de relações interpessoais. Refletir sobre a ideia de ação conectiva implica considerar as reconfigurações sociais promovidas pelas novas tecnologias, pelo grande volume de compartilhamentos de conteúdo e informações promovidas pela crescente presença da internet e aparelhos móveis, como os smartphones, na vida cotidiana dos sujeitos. Elementar à noção de ação conectiva, subjaz a ideia de que, nas sociedades contemporâneas, em que as "organizações formais estão perdendo o controle sobre os indivíduos, e os laços de grupo estão sendo substituídos por redes sociais fluidas e em larga escala", as novas redes construídas a partir da ação conectiva e não mais da ação coletiva "podem operar de maneira importante por meio dos processos organizacionais das mídias sociais, e sua lógica não exige um forte controle organizacional ou a construção simbólica de um 'nós' unido. A lógica da ação conectiva, sugerimos, implica uma dinâmica própria e, portanto, merece análise em seus próprios termos analíticos" (Bennett; Segerberg, 2012:748).

${ }^{6}$ Segundo os dados da pesquisa TIC Domicílios 2018, do Comitê Gestor da Internet no Brasil (CGI.br), embora o acesso à internet de banda larga tenha crescido no Brasil nos últimos anos e entre todas as classes sociais, atingindo $67 \%$ dos domicílios brasileiros, ainda há um descompasso significativo entre as classes sociais. As classes sociais $\mathrm{AB}$ apresentam mais de $94 \%$ dos domicílios com acesso à internet, essa porcentagem cai para $76 \%$ entre a classe C e $40 \%$ entre as classes DE. A pesquisa integral pode ser conferida no site da instituição. Disponível em: <https://cetic.br/pesquisa/domicilios/>.
} 
política e organizacional no sentido de uma "ação conectiva" como uma nova forma de ação dos sujeitos coletivamente organizados.

Contrariamente às abordagens que conferem forte peso analítico à internet na discussão sobre o caráter de novidade das novas formas de organização e associativismo contemporâneo, sejam os coletivos ou os "novíssimos movimentos sociais", como tem destacado Gohn $(2014 ; 2017 ; 2019)$, pensamos a internet e suas tecnologias a partir da ideia de um novo recurso nas estratégias de mobilização e ação das ações coletivas no atual contexto. Afinal, em termos históricos, trata-se de uma tecnologia nunca antes disponível às organizações sociais, e, ao que indica, tende a ser um repertório modular nas estruturas de mobilização ${ }^{7}$ - não somente entre os coletivos.

Certamente, mais relevante à discussão analítica é a reflexão trazida pela literatura de movimentos sociais respeitante à ressignificação de repertórios na disputa pelos enquadramentos interpretativos, isto é, o processo de atribuição de sentidos dos sujeitos coletivos a uma determinada situação (McAdam, McCarthy, Zald, 1999) ${ }^{8}$. Não parece haver dúvidas de que a internet tem proporcionado ou intensificado as disputas pelos enquadramentos sociais. Porém, isso não é um fato novo nas estratégias das ações coletivas. A novidade (ressignificada) em questão, tal como se percebe nas ações de coletivos, como o Mídia Ninja ${ }^{9}$, ou nos diversos coletivos de comunicação criados nas periferias brasileiras ${ }^{10}$, é que essas ações vão além do objetivo clássico de atrair a atenção da grande mídia como uma forma de disputar socialmente uma narrativa. As estratégias de mobilização e ação dos coletivos, não só dos coletivos de comunicação, têm demonstrado que no atual contexto das "sociedades informatizadas", tão ou mais importante do que o acesso à "grande mídia" é a

\footnotetext{
${ }^{7}$ Embora os repertórios de ação e organização possam se adaptados a diferentes situações e em diferentes contextos e/ou sofrerem incrementos ao longo do tempo, o uso recorrente (a rotinização) de determinadas formas de ação e organização geram ações "modulares". Um exemplo, como destaca Tarrow (2009:131), são as greves: "A greve oferece um bom exemplo de como as formas de confronto que começam de forma disruptiva tornam-se modulares e finalmente convencionais".

${ }^{8}$ Atribuir sentido é interpretar o contexto, avaliá-lo, identificando problemas, atribuindo responsabilidades e apontando possíveis soluções. A construção de enquadramentos interpretativos é essencial tanto para a compreensão da mobilização por parte dos analistas, como a ação e mobilização por parte dos sujeitos coletivos (Cf. Silva; Cotanda; Pereira, 2017).

${ }^{9}$ Como destaca em sua página no Facebook, o Midia Ninja é uma rede de comunicadores que, atuando a partir de uma lógica colaborativa de compartilhamento gratuito de conteúdos, tais como reportagens e documentários, "produzem e distribuem informação em movimento, agindo e comunicando". O coletivo ficou nacionalmente conhecido durante as manifestações de rua de 2013, ao transmitir ao vivo diversas manifestações e produzir documentários e reportagens nas redes sociais.

${ }^{10}$ Para uma leitura específica sobre os coletivos de comunicação, conferir os trabalhos de Andrade (2017) e de Assis (2018). O estudo de Assis (2018) fornece um bom cenário dos coletivos de comunicação das periferias paulistas. Já o de Andrade (2017) permite pensar conceitualmente os coletivos de comunicação e perceber tanto o contexto de emergência dessas experiências, e as crises que provocaram no campo jornalístico tradicional, quanto sua estrutura organizacional e de ação.
} 
construção de narrativas independentes por meio de mídias alternativas e politicamente orientadas (Andrade, 2017). No entanto, até onde temos percebido, ainda estamos distantes, tanto empírica como analiticamente, de poder afirmar que vivemos em um momento de radical reconfiguração político e organizacional suficiente para falarmos em "movimentos sociais em rede" (Castells, 2009; 2013) ou de "novíssimos movimentos sociais" (Gohn, 2014; 2019).

Desta forma, ao contrário de uma "novidade nunca antes vista", percebemos essa estratégia de mobilização e de ação como uma ressignificação estruturalmente inscrita de repertórios, uma vez que, há algumas centenas de anos, os movimentos operários e sindicais, por exemplo, já produziam seus próprios meios de comunicação para informar e mobilizar seus membros e apoiadores. Outro exemplo, mais atual, são as rádios comunitárias nas periferias brasileiras, as quais já atuavam nesse sentido pelo menos desde a década de 1970. A novidade atual, certamente, é a facilidade e a capacidade de atingir um maior número de pessoas em tempo real proporcionada pela expansão da internet, bem como pela crescente importância que as redes sociais e o ciberativismo têm demonstrado tanto para os ativistas quanto para os analistas (Castells, 2013).

Em suma, de uma forma mais geral, os coletivos têm sido comumente percebidos pela literatura como novas formas de mobilização, organização e de ação contemporânea pautadas nas ideias de coletividade, no trabalho colaborativo, no compartilhamento horizontalizado de informação de poder (decisão política no interior do grupo) e na criação de espaços e formas especiais de relações sociais entre os sujeitos (sem hierarquias, sem lideranças etc.). Esse argumento do "novo" surge porque, quando comparados conceitual e organizacionalmente pelos ativistas a outras estruturas sociais coletivas, como as ONG's, os grupos de interesses, os sindicatos e as organizações de movimentos socais mais formalizadas do ponto de vista estrutural, os coletivos surgem como um fenômeno híbrido, com certas características próprias referentes à dimensão organizacional, às demandas ou projetos políticos e às estratégias de mobilização e ação.

O percurso que fizemos até aqui não teve por objeto esgotar a ampla discussão que tem sido desenvolvida por pesquisadores de diferentes campos do conhecimento sobre os coletivos. Menos pretencioso, o objeto central desta seção foi apresentar uma sistematização e problematizar alguns dos principais traços apontados pela literatura como inerentes às diferentes experiências coletivas no atual contexto nacional, aqui estruturada a partir desses três eixos analítico-descritivos: dimensão organizacional, demandas elou projetos políticos e estratégias de mobilização e de ação. Na próxima seção, retomaremos alguns pontos aqui 
apresentados, problematizando-os a partir da análise dos sentidos mobilizados pelos sujeitos na identificação enquanto coletivos.

\section{Os sentidos mobilizados pelos sujeitos: ressaltando a posição diferencial e a liderança na construção da ideia de coletivos}

Temos percebido a construção da ideia de coletivo pelos ativistas a partir da demarcação de fronteiras conceituais nativas em relação aos significados sedimentados acerca das diferentes formas de mobilização, organização e ação da sociedade civil contemporânea, demarcando uma posição diferencial em relação, por exemplo, aos sindicatos, às ONG's, aos partidos e mesmo a determinadas organizações de movimentos sociais.

Por essa leitura, compreendemos que todo processo de identificação se constitui por meio de uma diferença (différance), de uma relação com um "outro" que a constitui no entrecruzamento das fronteiras "interna" e "externa"; uma relação que mantém um caráter necessário, porém não determinado, entre os lados fronteiriços (Staten, 1984; Mouffe, 2011; 2014). Nesses termos, uma "identidade", ou melhor, um processo de identificação, estará sempre já "contaminado" por um "algo além de si" que faz parte da sua identificação, isto é, o exterior constitutivo ${ }^{11}$. Não há, portanto, uma forma própria, uma essência na constituição da identificação; a identificação corre na e a partir da relação.

Os processos de identificação, portanto, ocorrem por meio da diferença, e isso é fundamental para tornarmos clara a noção de exterior constitutivo e sua importância nos processos de identificação (Hall, 2000; 2011):

[...] é apenas por meio da relação com o Outro, da relação com aquilo que não é, com precisamente aquilo que falta, com aquilo que tem sido chamado de seu exterior constitutivo, que o significado "positivo" de qualquer termo - e, assim, sua "identidade" - pode ser construído (Hall, 2000:110).

Nesse processo, ao construírem suas próprias identidades coletivas, "afinal, o que é um coletivo?", os ativistas têm mobilizado e atribuído uma série de sentidos a outras organizações societárias, tais como "estruturas constituídas por arranjos institucionais fortemente burocratizados", "organizações hierarquizadas", "centralizadas na figura da liderança". Para demarcarem uma posição diferencial, cujos significados são percebidos mais claramente quando analisados a partir de sua inscrição na conjuntura de crítica à "política

\footnotetext{
${ }^{11}$ Como destaca Staten (1984:23), “a noção de exterior constitutivo é a desconstrução alternativa ao conceito filosófico fundamental de forma e essência - isto é, de unidade e auto-identidade como os mais gerais e invioláveis limites (seja estritamente transcategórico ou não) do ser do conhecimento".
} 
tradicional", estruturada, sobretudo, a partir das ondas de protestos de 2013, os sentidos mobilizados pelos sujeitos na construção da ideia de coletivos denotam (i) uma estrutura organizacional moderna, sem hierarquias, destituídas da figura central da "liderança política histórica" e (ii) um tipo de agrupamento ou organização de caráter mais dinâmico, baseado em laços afetivos, ação horizontalizada, ação política direta, e a partir de um forte sentimento de autonomia dos sujeitos tanto em relação uns aos outros como em relação a outras organizações sociais e políticas, o que, como vimos anteriormente, não necessariamente significa uma recusa da participação em espaços e a utilização de recursos e mecanismos institucionais para sua ação.

Os sentidos são percebidos através de questionamentos feitos para os ativistas em relação ao porquê deles se organizarem e de quais são as suas percepções como coletivos e não outras formas de mobilização, organização e ação. As respostas expressaram recusa a certos traços organizacionais de outras experiências organizacionais societárias:

Eu acredito que é um trauma já [recusa do termo movimentos sociais]. Porque, por exemplo, dentro do contexto do movimento hip-hop, outro dia atrás, eu estava conversando com alguns dos caras que são bem das antigas do movimento [...] e eles falavam que como funcionava o movimento hip-hop... Se você pegar aí o período dos anos 90, o que as pessoas vão falar do movimento negro no Espírito Santo? Da rigidez do movimento no Espírito Santo [...] dos caras quererem falar: "É assim, assim, e ponto". E o hip-hop era o mesmo jeito. Para uma pessoa poder falar no movimento hip-hop, tinha que passar lá antes, falar com os caras, os caras faziam uma coisa de juiz mesmo: "Pronto, pode. Agora você pode falar". Já o coletivo tem uma liberdade por si só. É aquilo, ele vê uma demanda, ele vai lá e soluciona a demanda. Não precisa ir lá pedir autorização para alguém para solucionar. (Entrevistado 1. Entrevista cedida no dia 20 de fevereiro de 2019).

Coletivo é uma maneira de se organizar em grupo. Um sindicato é um coletivo? É, mas aí já é uma forma institucional que já é dada, classicona. Os coletivos, talvez, não caminhem para um arranjo institucional tão claro, tão rígido [...]. Pra mim, um movimento social é uma coisa mais ampla. Um movimento social, pra mim, é composto de instituições, de ativistas avulsos, coletivos. Pra mim é algo maior [...]. (Entrevistado 2. Entrevista cedida no dia 12 de fevereiro de 2019).

É totalmente diferente de uma ONG, por exemplo... Eu acredito que ONG é algo que já é pensado dentro de um gesso [...]. A ONG, eu acho... É muito engessada, e muitas coisas você não consegue realizar através da ONG, porque tem uma pessoa jurídica ali respondendo por aquilo. Pode ser um medo também, de queimar a imagem [não querer ser uma ONG]. Os coletivos talvez sejam mais fluídos. (Entrevistado 5. Entrevista cedida no dia 01 de março de 2019).

O que podemos perceber nesse exercício distintivo operado pelos ativistas é que ao darem relevo e ao negarem discursivamente traços de outras lógicas organizacionais e de socialização, vistas como estruturas rígidas, verticalizadas etc., estas passam a exercer um papel referencial discursivo para os sujeitos no processo de identificação enquanto coletivos. Nessa construção discursiva, os movimentos sociais, as ONG's, os sindicatos, os partidos 
políticos, dentre outras experiências organizacionais, surgem como exterior constitutivo (Staten, 1984) na estruturação da relação diferencial.

Essa demarcação da posição diferencial do "nós" ("somos um coletivo") depende de uma correspondência que ao mesmo tempo em que excede a identidade coletiva, a constitui ("somos um coletivo porque não somos movimentos, ONG's etc."), evidenciando, dessa forma, a necessidade de uma relação com o elemento externo para a constituição da "unidade interna" - por isso exterior constitutivo ${ }^{12}$. É por essa leitura diferencial que compreendemos tanto os esforços descritivo-analíticos da literatura sobre os coletivos quanto as narrativas dos ativistas no momento em que ambos, literatura e ativistas, buscam destacar a distinção dos coletivos em relação a outras experiências organizacionais ${ }^{13}$.

Nesse processo reflexivo, os sujeitos buscam construir para o grupo aquilo que Desouza (2012), ao analisar diferentes coletivos de mulheres na Índia, designa como "ideologia coletiva", entendida como um conjunto de valores diretamente relacionados ao fortalecimento da lealdade, solidariedade e compromisso intra-sujeitos e entre os sujeitos e o coletivo:

(a) Um conjunto de valores fundamentais, identificados pelo grupo, que orienta as atividades da organização. Os valores centrais que também asseguram a manutenção da ideologia da organização.

(b) A adoção de uma abordagem holística, em que os indivíduos que compõem a organização são considerados tão importantes quanto a própria organização, a qual ajuda a fortalecer o laço coletivo, propagar o espírito coletivo e possibilitar o funcionamento coletivo.

(c) Na organização coletiva, o indivíduo e o grupo estão inter-relacionados e, como resultado, todo indivíduo é importante para o grupo. A construção de equipes ${ }^{14}$, portanto, é um componente importante da organização coletiva. $\mathrm{O}$ foco nos exercícios de construção de equipe (i) ajuda na construção de laços entre os membros, (ii) permite que os membros se familiarizem com o background e a ideologia de todos os membros, (iii) confrontem opiniões diferentes, personalidades e outros conflitos interpessoais que possam surgir e (iv) permite que os membros localizem e articulem suas próprias necessidades dentro dos objetivos maiores da organização (Desouza, 2012:388. [destaques nossos]).

O que essa "ideologia coletiva” destaca, portanto, é que essas novas coletividades buscam outra lógica de organização e de socialização entre os sujeitos - o que também se

\footnotetext{
12 Para uma leitura um pouco mais detida sobre o conceito de exterior constitutivo aqui mobilizado, conferir Marques (2020).

13 O estudo de Andrade (2017) sobre a constituição dos coletivos de comunicação em face dos veículos jornalísticos tradicionais, e o de Lima (2018), na análise do ENUDS e da diferenciação de suas organizações em relação ao movimento LGBT e ao movimento estudantil, embora não problematizem nos mesmos termos, também apontam mais claramente para essa direção analítico-teórica.

${ }^{14}$ No original, o termo surge como Team building. Refere-se a vários tipos de atividades direcionadas ao aprimoramento das relações sociais de um determinado grupo, bem como para definição de papeis dentro do grupo; frequentemente envolvendo tarefas colaborativas.
} 
percebe na literatura nacional sobre os coletivos contemporâneos (Cf. Mesquita, 2008; Borelli; Aboboreira, 2011; Gohn, 2017; Lima, 2018).

Nesse processo, os sujeitos, muitas vezes em uma posição crítica às experiências associativas por eles anteriormente vivenciadas, valorizam o compartilhamento de ideias entre si, como forma de descentralização da informação e de enriquecimento do aprendizado coletivo, reforçam os laços afetivos, importantes no processo de estruturação das relações entre os ativistas, ressaltam a importância do trabalho colaborativo, como uma maneira de potencializar a criação e o fortalecimento das decisões consensuais, defendem o princípio da autonomia da ação, como possibilidade de empoderamento dos sujeitos, e, objetivando a construção de espaços de vivência e de trabalho destituídos de hierarquia e da figura central da liderança, desconstroem os sentidos sedimentados de representação (formal) e de delegação (vertical) comumente impressos às ideias de "liderança" e "burocracia" (Mesquita, 2008; Maia, 2013; Borelli; Aboboreira, 2011; Gohn, 2014; 2019; Lima, 2018; Desouza, 2012; Perez, 2019).

Dentre esses importantes elementos, queremos nos deter um pouco mais em um em especial. A ideia de liderança tem ganhado um destaque especial da literatura, seja em relação à lógica organizacional, seja respeitante à lógica de socialização (Bordt, 1997; Desouza, 2012; Gohn, 2017; Perez; Silva Filho, 2017; Maia, 2013; Lima; Schmitz, 2017; Lima, 2018). Nesse debate, é comum entre ativistas e analistas o argumento de que "os coletivos não têm liderança". É preciso olhar com mais atenção para essa questão.

Desde os primeiros contatos com o universo dos coletivos culturais no contexto capixaba, sempre que buscávamos por informações sobre algum coletivo, seja com ativistas, seja com atores estatais, era comum a indicação dos mesmos ativistas, dando pistas de que esses sujeitos poderiam possuir algum tipo de "destaque" no campo ativista. A despeito dos argumentos da literatura e, em certa medida, dos ativistas sobre a ausência de lideranças, esses indícios insistiam em apontar para presença de "sujeitos proeminentes" no interior dessas experiências organizacionais.

Isso também parece ser percebido por Gohn (2019:143) que destaca os papeis dos "mediadores" e dos "editores" das ações dos coletivos, compreendo-os não como liderança stricto sensu, mas como sujeitos que exercem alguma "referência". Como destaca, esses sujeitos apresentam grande protagonismo na ação coletiva, "não como liderança, mas como ativadores e pontos de referência. São muitos e não se concentram na figura de um líder principal”. 
Isso reforçou nossa inquietação sobre os "sujeitos proeminentes" do campo. De fato, os elementos que surgiram não indicam uma liderança nos mesmos termos tradicionais de lideranças de partidos de massa, lideranças de associações de moradores ou em certas organizações de movimentos sociais. A partir disso, buscamos analisar quais os sentidos da ideia de liderança nos coletivos, pois, ao que tudo indicava, a recusa dos sentidos estava baseada em um certo conjunto de significados do que representaria o significante liderança em outras organizações societárias, e não uma completa ausência dessa função, ainda que estruturada em outros termos.

Com esse movimento analítico, temos percebido, até aqui, que a questão pode ser menos a inexistência de lideranças e mais a desconstrução discursiva de sentidos que se relacionam às ideias clássicas, sedimentadas, desse significante em outras experiências político-organizacionais:

Todo mundo fala muito em liderança, mas fala de liderança em negócios. Não pensa que a liderança vai além disso. Liderança ultrapassa todos esses limites aí. Então, quem que vai lá ver a casa que a gente vai ficar? Quem deu a ideia? Quem propõe, põe? Sacou? É isso. Então, tem essa coisa [que] você também tem que se ligar [...]. A liderança vem da parte administrativa, pagar contas, toda essa parte administrativa [...]. O maior conflito de um coletivo, digamos assim, se você quiser ser organizado, um coletivo que quer se organizar, é definir quem faz o que. (Entrevistado 3. Entrevista cedida no dia 27 de fevereiro de 2019).

Não, alguma hierarquia com certeza vai ter, é uma hierarquia natural. Porque a hierarquia surge do modo seguinte: um coletivo de 10 pessoas, pela minha experiência de atuação em coletivos, já participei em vários, eu noto que se não tiver 1 ou 2 ali que puxam, que não necessariamente são os donos, o topo da hierarquia, mas se não tiver esses 1 ou 2 aí que puxam mesmo a coisa, o coletivo vai esfriando [...]. Mas, pensando nesse modo como eu disse, sobre o coletivo que funciona, onde cada um faz as suas coisas e estão conectados de algum modo. Porque assim, desse modo, todo mundo pode fazer muita coisa sozinho, inclusive sem pedir autorização pro outro. Eu acho que isso é uma confiança do coletivo. O coletivo precisa ser formado desse modo, precisa ter confiança em quem faz parte do coletivo. (Entrevistado 5. Entrevista cedida no dia 01 de março de 2019).

Essa desconstrução é diferente do argumento de inexistência da função de liderança. Por essa leitura analítica, compreendemos que quando os ativistas afirmam não possuírem lideranças, estão se referindo a certos significados que conformam a ideia sedimentada pelos discursos políticos e, em grande medida, pelo discurso acadêmico de liderança. Os sentidos mobilizados pelos sujeitos não são os mesmos daqueles comuns às lideranças de estruturas organizacionais mais rígidas e centralizadas em um ou em poucos indivíduos, ou em uma liderança formal. A questão, como a temos compreendido, não é simplesmente uma total inexistência de lideranças, mas uma ressignificação dos sujeitos do significante liderança - e, mais amplamente, dos repertórios organizacionais e de ação. 
Nessa ressignificação, a liderança deixa de ser algo delegado ou obtido por meio de processos institucionais ou sedimentado em atributos pessoais, como o carisma. Se questionarmos os ativistas sobre os sentidos de liderança relacionados às formas organizacionais históricas (partidos, movimentos sociais, ONG's etc.), ou se procurarmos observar sua presença nas práticas organizacionais e políticas cotidianas dos coletivos, certamente constataremos que essas organizações simplesmente não se pautam em princípios de lideranças. Os sentidos que temos percebido nos coletivos são mais de "referência", de pessoas que estão a mais tempo atuando no campo, e uma liderança de caráter mais circunstancial.

Em nossas atividades de campo, temos analisado esse caráter circunstancial não como uma simples alternância estratégica ou pragmática entre os ativistas. A liderança circunstancial comumente encontra relação no momento de maior disponibilidade de determinados ativistas na dedicação à organização, tendo mais tempo para responder pelo coletivo, ou se relaciona à direção da execução de uma ação ou projeto específico, ainda que a execução venha a ser coletiva. Isso é comum, por exemplo, nos casos em que um ativista tem um projeto nominal submetido e aprovado junto às políticas de captação de recurso via editais públicos, mas sua execução se processa coletivamente pelo coletivo do qual faz parte ou mediante o convite de um sujeito a um coletivo parceiro. Nesse caso, esse sujeito exerce uma função de liderança que é relacional, ela se explica e se apresenta em um contexto situado.

A questão que surge, portanto, pode estar na distância entre como os sujeitos ativistas e analistas - significam a ideia de liderança. Se, como analistas, a compreendermos de forma rígida, centralizada em um ou poucos indivíduos, constituída por mecanismos formais, certamente não a encontraremos na maior parte das experiências coletivas contemporâneas, o que não significa, necessariamente, uma total ausência de significados e funções de liderança nessas novas estruturas organizacionais: trata-se de um fenômeno coletivo cujos sentidos de liderança são constantemente desconstruídos, uma liderança que deve ser analisada no interior das relações em curso, tornando-se uma "liderança ausente", ainda que necessária para uma organização ${ }^{15}$.

Como dissemos no início desta seção, a literatura sobre os coletivos se apresenta como um esforço em construção. Visando contribuir com esse debate, o que destacamos até aqui

\footnotetext{
${ }^{15}$ Dizer que é necessária, no entanto, difere dos argumentos "Lei de ferro das oligarquias" de Michels (2001). A função de liderança é necessária, como destacam os próprios ativistas, no processo de organização e mobilização da ação e na construção de um padrão mínimo de estruturação do trabalho coletivo. No entanto, torna-se "ausente" devido à ação reflexiva dos sujeitos de desconstruir formações burocráticas oligárquicas diante da busca por outras formas de organização, socialização e de tomada de decisões.
} 
são os principais elementos discursivos que temos percebido na análise dos sentidos mobilizados pelos sujeitos na identificação enquanto coletivos e que, em alguma medida, divergem da literatura. Como buscamos sustentar, trata-se de uma construção de uma posição diferencial em relação a outras experiências organizacionais, políticas e de socialização. Nesse processo, os coletivos têm se apresentado como uma instigante novidade. O que podemos problematizar é a dimensão dessa "novidade" em termos analíticos particulares. Estamos diante de uma nova categoria analítica ou temos exacerbado certos elementos e discursos nativos evocados em um contexto particular de crítica à "política tradicional". É com essa reflexão, como notas finais, que gostaríamos de encerrar o artigo.

\section{Notas conclusivas: uma nova categoria analítica?}

As novidades respeitantes à dimensão organizacional, às demandas elou projetos políticos e às estratégias de mobilização e de ação trazidas pelas experiências dos coletivos e ressaltadas pela literatura, têm apontado, cada vez mais, para uma direção: os coletivos representam novidades no que diz respeito à forma de organização e à mobilização da sociedade civil contemporânea. A partir desse indicativo, gostaríamos de problematizar a potencialidade dos coletivos se posicionarem com uma categoria analítica específica, sem, com isso, esgotar a discussão.

A principal distinção destacada pela literatura na análise sobre os coletivos é realizada em relação aos movimentos sociais (Cf. Gohn, 2017; 2019; Perez; Souza, 2017; Lima, 2018). Isso ocorre, centralmente, porque é justamente com essa forma de organização da ação coletiva que os coletivos analiticamente mais se assemelham. Nessa problematização, pelo menos mais dois elementos podem ser mobilizados a partir da literatura de movimentos sociais: o caráter da sustentação da ação e a dimensão conflitiva.

Poderíamos argumentar que diferentemente dos movimentos sociais, percebidos pela literatura especializada como experiências mais estruturadas, com clara identificação de opositores, com demandas ou projetos políticos percebidos como mais estruturais do ponto de vista das transformações sociais e como organizações mais coesas do ponto de vista da identidade coletiva (Diani, 2015; Della Porta; Diani, 2015), os coletivos, devido à própria dimensão organizacional e à construção de demandas elou projetos políticos destacados anteriormente, têm sido percebidos como organizações cujas ações têm um caráter menos permanente, o que tenderia a levar a constantes recomeços marcados por novas reformulações de pautas (Maia, 2013). 
Assim como em Maia (2013) - mas também poderíamos citar as contribuições de Perez e Silva Filho (2017) e Peres e Souza (2017) ao debate entre coletivos e movimentos sociais -, Gohn (2017:27) percebe que os coletivos, em contraste com os movimentos sociais, possuem um caráter circunstancial, não visando necessariamente uma continuidade: "São similares a instants mobs, eventos combinados nas redes sociais para promover uma ação específica no tempo e no espaço, impactar um coletivo e se dissolver”.

Não discordamos do caráter flexível e menos permanente do ponto de vista da sustentação da ação contenciosa dos coletivos. Mas isso não significa, necessariamente, uma ação mobilizada para ser momentânea (flash mobs). É preciso ter em vista que os coletivos, bem como os espaços cotidianos por eles construídos ${ }^{16}$, são fenômenos dinâmicos e que estão, comumente, em constante reestruturação. Como destaca Paim (2009:29) em sua análise sobre os coletivos culturais, da mesma forma que os coletivos são rapidamente compostos e, pouco depois, são decompostos, os ativistas conseguem se agrupar em outra formação. Isso ocorre porque os coletivos "obedecem à lógica da mobilidade, da contingência de sua época e de suas sociedades", e não a uma lógica estrutural, formal e rígida do ponto de vista organizacional e da construção de agendas e projetos políticos. Dessa forma, a análise também deve considerar o contexto estratégico-relacional no qual estão inscritos, isto é, a conjuntura política e os padrões e a dinâmica das inter-relações entre as esferas societária e institucional, bem como as próprias urgências dos sujeitos coletivos. Flexíveis, dinâmicos e altamente inventivos, os coletivos conseguem se reestruturar com facilidade e somente nesse sentido podemos falar em "descontinuidade" ou "caráter circunstancial". A questão que fica em aberto é: até que ponto essas características de fato diferem das experiências de organizações de movimentos sociais menos estruturadas, de caráter mais local?

Essa questão do caráter menos permanente da ação dos coletivos face outras organizações societárias foram perceptíveis em dois casos significativos que presenciamos durante nossas recentes atividades de campo no contexto capixaba. Um foi o da transformação de um coletivo em empresa social e outro da construção de uma ONG's com esfera estatal e econômica a partir da articulação de coletivos entre si.

O primeiro caso foi o Coletivo Expurgação. O Expurgação, uma das experiências no campo cultural mais antigas, com maior estrutura formal e em atuação no contexto capixaba,

\footnotetext{
${ }^{16}$ Os espaços cotidianos é o termo utilizado por Paim (2009) para se referir aos espaços próprios criados pelos coletivos como uma alternativa aos espaços artístico-culturais tradicionais (museus, galerias etc.). Como exemplos de espaços cotidianos, podemos pensar os ateliês coletivos, em que diferentes artistas e coletivos expõem e comercializam seus produtos, ou as "casas coletivas", estrutura pensada como residência e espaço de trabalho e socialização coletiva, comum a diferentes coletivos.
} 
foi criado, em 2008, por um grupo de estudantes do curso de Desenho Industrial da Universidade Federal do Espírito Santo (UFES). Todavia, como narrou o entrevistado ${ }^{17}$, após certa expertise organizacional e técnica (produção cultural, produção audiovisual, produção comercial etc.), o Expurgação, a partir de 2010, ganhou contornos empresariais: "Continua o Expurgação, mas assim, mais na parte empresarial; e a parte do coletivo é alguma coisa de música que surge de vez em quando e algum projeto que chama todo mundo para trabalhar".

O segundo caso verificado foi o Instituto Tamojunto, que, como destacou o nosso entrevistado $^{18}$, sempre teve a preocupação de fortalecer as ações dos coletivos juvenis dentro dos territórios das comunidades da grande Vitória. A partir dessa preocupação, diferentes formações coletivas voltadas para o movimento hip-hop e funk, já existentes nas periferias, começaram a se articular e a buscar por fontes de recursos para suas ações. Foi a partir de então que eles passaram a acessar as políticas culturais do Governo do Estado. Como nos narrou o entrevistado, nessa interação entre os coletivos em articulação e a esfera estatal surgiu a ideia de construir uma instituição voltada para as suas experiências coletivas, "e aí surgiu o Instituto Tamojunto. O Instituto [também] captou um recurso privado e fez um projeto chamado Caiu na Rede é Jovem. E o Caiu na Rede é Jovem era um projeto para incubação de coletivos":

Pergunta: Então, inicialmente, o Tamojunto era uma ONG que foi criada pelos próprios coletivos? [em 2014 se tornou uma OSCIP].

Entrevistado: Isso, por um grupo de coletivos, que vieram da periferia, especificamente, articulado com outras organizações. (Entrevistado 1. Entrevista cedida no dia 20 de fevereiro de 2019).

Esses casos ajudam a perceber o quão complexo é o fenômeno em tela. Quando comparados a outras organizações sociais, os coletivos não só possuem demandas e/ou projetos políticos de caráter mais flexível e interseccional, como também, ao se articularem com outros coletivos, organizações de movimentos sociais, com a esfera institucional ou com setores da esfera econômica, podem se reestruturar ou mesmo dar origem a outras formas organizacionais - isso não necessariamente significa que esse processo seja uma característica apenas dos coletivos.

Voltando à literatura especializada de movimentos sociais, além da dimensão estrutural, pensada como a criação de densas redes mais ou menos informais de organizações de movimentos, da dimensão simbólica, relacionada ao compartilhamento de uma identidade

\footnotetext{
${ }^{17}$ Entrevistado 3. Entrevista cedida no dia 27 de fevereiro de 2019.

${ }^{18}$ Entrevistado 1. Entrevista cedida no dia 20 de fevereiro de 2019.
} 
coletiva coesa e diferenciada, a dimensão conflitiva, pensada mais amplamente como a sustentação de relações conflitivas com oponentes claramente identificados, surge como um dos principais elementos teórico-analíticos distintivos entre movimentos sociais e outras formas de ação coletiva (Cf. Diani; 1992; 2015; Della Porta; Diani, 2015). Por essa leitura, e considerando a dimensão organizacional, as demandas elou projetos políticos e às estratégias de mobilização e de ação na análise dos coletivos, percebemos implicações teóricas significativas na relação movimentos-coletivos.

Como destacam Della Porta e Diani (2015:41), é elementar à discussão sobre movimentos sociais que nem toda ação coletiva, pensada mais amplamente como a agregação de "indivíduos que compartilham recursos na perseguição de metas coletivas", se estrutura em termos de movimentos sociais. Novamente, é o caráter da sustentação da ação e a dimensão conflitiva que ganham centralidade. Acreditamos que o primeiro elemento foi devidamente discutido ao longo do texto, resta-nos avançar um pouco mais sobre a dimensão conflitiva para concluirmos essa reflexão.

A ideia de conflito, entendida como uma "relação de oposição entre atores que buscam controlar o mesmo objeto, seja poder político, econômico ou cultural, e, em processo, produzem demandas negativas um em relação ao outro" (Della Porta; Diani, 2015:43), é central para a distinção entre movimentos sociais e outras formas de ação coletiva, pois, como destacam os autores, "o simples fato de apresentar problemas coletivos, produzir bens públicos ou expressar apoio a certos valores ou princípios morais, não corresponde automaticamente à ação de um movimento social”. Para conceber analiticamente uma ação coletiva como movimento social, é necessário, portanto, uma clara identificação de oponentes políticos, sociais ou culturais, a sustentação de relações conflitivas com esses opositores e a criação de redes.

De um ponto de vista teórico-analítico, esse enfoque, sem uma devida flexibilização, pode dificultar as análises de experiências associativas contemporâneas cujas ações variam entre conflito e colaboração, nas quais a ideia de sustentação da ação não corre, portanto, estritamente em termos conflitivos. Nesses termos, a construção da ideia de inimigo é menos clara, ou ao menos não se dá em termos absolutos - uma alternativa é a construção de outras categorias analíticas próximas a de movimentos sociais, como organizações de consenso, coalizações etc. (Cf. Diani, 2015). Levada às últimas consequências, esse enfoque pode culminar tanto em leituras que consideram as organizações sociais como elementos necessariamente extrainstitucionais (dimensão de externalidade), quanto naquelas que compreendem que qualquer tipo de inter-relação não conflitiva, ou não exclusivamente 
conflitiva, seja uma relação de cooptação ou instrumentalização das organizações sociais pela esfera institucional.

É nesse sentido que Gohn (2019:114) tende a contestar a mobilização da literatura sobre movimentos sociais, sem uma devida reflexão, para se pensar os coletivos. Isso porque, como destaca a autora, "muitos deles não têm um adversário, um antagonista claro, nos termos de uma teoria de Touraine. Outros não constroem identidades a partir de pertencimento originários, culturais, mas formam por adesão a uma causa que lhes traz retorno". Além disso, como também observa Gohn, os coletivos, a depender do contexto estratégico-relacional, podem ou não atuar através de relações conflitivas e em redes movimentalistas.

São devidos a esses pontos de convergência e de distinção com relação a outras formas de organização e mobilização da sociedade civil, que o tema "coletivos" tem ganhado crescente destaque nos estudos sobre ação coletiva, movimentos sociais, sociedade civil e inter-relações com o Estado. Trata-se de uma nova categoria analítica? Acreditamos que somente o tempo e as novas reflexões poderão apresentar respostas mais satisfatórias.

Só não podemos perder de vista, como destaca Diani (2015), que a conclusão de que determinadas formas de ação coletiva não sejam propriamente movimento social não implica que sejam experiências de menor importância analítica ou política. Essa conclusão pode apenas indicar que, a despeito das heranças de repertórios, há processos organizativos e formas de coordenação da ação coletiva analiticamente distintos.

\section{Referências}

ANDRADE, Samária (2017), "Poder e legitimidade no campo do Jornalismo: os Coletivos de Comunicação e as tensões de um modelo em xeque". In: $18^{\circ}$ Congresso Brasileiro de Sociologia. Anais... Brasília. Disponível em: http://www.adaltech.com.br/anais/sociologia2017/resumos/PDFeposter-trab-aceito-1164-1.pdf [Consult. 30-05-2019].

ASSIS, Larissa G. (2018), "Virada comunicação: como coletivos de comunicação das periferias estão construindo uma nova forma de se comunicar". Revista Anagrama, v. 12, n. 1, pp. 1-10. Disponível em: http://www.revistas.usp.br/anagrama/article/view/146727 [Consult. 30-05-2019].

BENNETT, Lance W.; SEGERBERG, Alexandra (2012), "The Logic of Connective Action". Information, Communication \& Society, v. 15, n. 5, pp. 739-768. Disponível em: https://doi.org/10.1080/1369118X.2012.670661 [Consult. 30-10-2019].

BORDT, Rebecca L. (1997), "How alternative ideas become institutions: the case of feminist collectives". Nonprofit and Voluntary Sector Quarterly, v. 26, n. 2, pp. 132-55. Disponível em: https://doi.org/10.1177/0899764097262003 [Consult. 30-05-2019]. 
BORELLI, Helena S.; ABOBOREIRA, Ariane (2011), "Teorias/metodologias: trajetos de investigação com coletivos juvenis em São Paulo/Brasil". Revista Latinoamericana de Ciencias Sociales, Niñez y Juventud, Manizales, v. 1, n. 9, pp. 161-72. [Consult. 30-05-2019]. Disponível em: http://www.scielo.org.co/pdf/rlcs/v9n1/v9n1a09.pdf

BORELLI, Silva H. S.; ROCHA, Rose M.; OLIVERIA, Rita C. A.; RANGEL, Lucia H. V.; LARA, Marcos R. (2010), "Jovens urbanos, ações estético-culturais e novas práticas políticas: estado da arte (1960-2000)". In S. V. Alvaradoara; P. A. Vommaro, Jóvenes, cultura y política en América Latina: algunos trayectos de sus relaciones, experiencias y lecturas 1960-2000. Rosario, Homo Sapiens Ediciones, pp. 293-324.

CASTELLS, Manuel (2009), A sociedade em rede. V. 1. São Paulo, Paz e Terra.

(2013), Redes de indignação e esperança: Movimentos sociais na era da internet. Rio de Janeiro, Zahar.

CLEMENS, Elisabeth S. (2010), "Repertórios organizacionais e mudança institucional: grupos de mulheres e a transformação da política nos EUA, 1980-19920". RBCP, n. 3, pp. 161-2018. Disponível em: http://periodicos.unb.br/index.php/rbcp/article/view/1679/1477 [Consult. 30-052019].

DELLA PORTA, Donatella; DIANI, Mario (2015), Los movimentos sociales. Madrid, UCM.

DESOUZA, Shaila (2012), "The Strength of Collective Processes: An 'Outcome Analysis' of Women's Collectives in India”. Indian Journal of Gender Studies, v. 19, n. 3, pp. 373-92. Disponível em: https://doi.org/10.1177/097152151201900302 [Consult. 30-05-2019].

DIANI, Mario (1992), “The Concept of Social Movement". The Sociological Review, v. 40, n. 1, pp. 1-25. Disponível em: https://doi.org/10.1111/j.1467-954X.1992.tb02943.x [Consult. 30-05-2019].

. (2015), "Revisando el concepto de movimento social". ENCRUCIJADAS. Revista Crítica de Ciencia Sociales, n. 9, pp. 1-16 [Consult. 28-08-2019]. Disponível em:

http://www.encrucijadas.org/index.php/ojs/article/view/161/145

GOHN, Maria da G. (2014), Sociologia dos movimentos sociais. São Paulo, Cortez.

. (2017), Manifestações e protestos no Brasil: correntes e contracorrentes na atualidade. São Paulo, Cortez.

. (2019), Participação e democracia no Brasil: da década de 1960 aos impactos pós-junho de 2013. Petrópolis, Vozes.

LACLAU, Ernesto; MOUFFE, Chantal (2015), Hegemonia e estratégia socialista: por uma política democrática radical. São Paulo, Intermeios.

LIMA, Elcimar M. O.; SCHMITZ, Heribert (2017), "Como os coletivos se mobilizam desde as manifestações de junho de 2013 em Belém”, In: 18 Congresso Brasileiro De Sociologia. Anais... Brasília: SBS [Consult. 30-05-2019]. Disponível em:

http://www.adaltech.com.br/anais/sociologia2017/lista_area_GT22.htm

LIMA, Stephanie (2018), “'Coletivo', 'ativista' e 'horizontal': uma análise de categorias em uso no movimento social contemporâneo". Teoria e Cultura, v. 13, n. 1, pp. 18-34. Disponível em: https://periodicos.ufjf.br/index.php/TeoriaeCultura/article/view/12382 [Consult. 06-04-2019]. 
MAIA, Gretha L. (2013), "A juventude e os coletivos: como se articulam novas formas de expressão política". Revista Eletrônica do Curso de Direito da UFSM, v. 8, n. 1, pp. 58-73. Disponível em: https://periodicos.ufsm.br/revistadireito/article/view/8630/pdf [Consult. 20-12-2018].

MARQUES, Marcelo de S. (2020), "Status ontológico da teoria do Discurso (tD) em laclau e Mouffe: Diálogos, perspectivas teóricas e conceitos básicos". Dados, v. 63, n.2, pp. 1-33. Disponível em: https://www.scielo.br/pdf/dados/v63n2/0011-5258-dados-63-2-e20180242.pdf [Consult. 15-072020].

McADAM, Dough.; McCARTHY, John D.; ZALD, Mayer N. (1999), "Oportunidades, estructuras de movilización y procesos en marcadores: hacia una perspectiva sintética y comparada de los movimientos sociales". In (Orgs). Movimientos sociales: perspectivas comparadas. Madrid, Istmo, pp. 21-46.

MESQUITA, Marcos R. (2008), "Cultura e política: A experiência dos coletivos de cultura no movimento estudantil". Revista Crítica de Ciências Sociais, Coimbra, n. 81, pp. 179-207. Disponível em: https://journals.openedition.org/rccs/660 [Consult. 30-05-2019].

MICHELS, Robert (2001), Para uma Sociologia dos partidos políticos. Lisboa, Antígona.

MOUFFE, Chantal (2011), Em torno a lo político. Buenos Aires, Fondo de Cultura Económica.

(2014), Agonística: pensar el mundo politicamente. Buenos Aires, Fondo de Cultura Económica.

PAIM, Claudia (2009), Coletivos e iniciativas coletivas: modos de fazer na América Latina contemporânea. Tese (Doutorado em Artes Visuais) - Instituto de Artes, Programa de PósGraduação em Artes Visuais, Universidade Federal do Rio Grande do Sul. Porto Alegre.

PEREZ, Olívia C. (2019), "Relações entre coletivos com as Jornadas de Junho". Opinião Pública, Campinas, v. 25, n. 3, pp. 577-596. Disponível em: http://www.scielo.br/pdf/op/v25n3/1807-0191op-25-3-0577.pdf [Consult. 24-03-2020].

PEREZ, Olívia C.; SILVA FILHO, Alberto L. A. (2017), "Coletivos: um balanço da literatura sobre as novas formas de mobilização da sociedade civil". Latitude, v. 11, n. 1, pp. 255-94. Disponível em: http://www.seer.ufal.br/index.php/latitude/article/view/2812/pdf_1 [Consult. 30-05-2019].

PEREZ, Olívia C.; SOUZA, Bruno M. (2017), "Velhos, novos ou novíssimos movimentos sociais? As pautas e práticas dos coletivos", In: $41^{\circ}$ Encontro Anual da ANPOCS. Anais... Caxambú: ANPOCS. Disponível em: https://www.anpocs.com/index.php/papers-40-encontro-2/gt-30/gt1115/10696-velhos-novos-ou-novissimos-movimentos-sociais-as-pautas-e-praticas-dos-coletivos/file [Consult. 30-05-2019].

PIRES, Ericson (2017), Cidade ocupada. Rio de Janeiro, Aeroplano.

REZENDE, Renato; SCOVINO, Felipe (2010), Coletivos. Rio de Janeiro, Editora Circuito.

ROSAS, Ricardo (2004), "Nome: coletivos, senha: colaboração". Guia de Navegação FindEtático. São Paulo, pp. 7-8. Disponível em: https://midiatatica.desarquivo.org/2002-2005/findetatico-guia-denavegacao/ [Consult. 31-05-2019].

(2005), "Notas sobre o coletivismo artístico no Brasil". Rua, Campinas, v. 12, n. 1, pp. 27-35. Disponível em: https://periodicos.sbu.unicamp.br/ojs/index.php/rua/article/view/8640786/8323 [Consult. 04-03-2019]. 
SILVA, Marcelo K.; COTANDA, Fernando C.; PEREIRA, Matheus M. (2017), "Interpretação e Ação Coletiva: o 'enquadramento interpretativo' no estudo de movimentos sociais". Revista Sociologia \& Política, v. 25, n. 61, pp. 143-64. Disponível em: http://www.scielo.br/pdf/rsocp/v25n61/01044478-rsocp-25-61-0143.pdf [Consult. 30-05-2019].

STATEN, Henry (1984), Wittgensteim and Derrida. Lincoln, University of Nebraska Press.

TARROW, Sidney (2009), O poder em movimento. Movimentos sociais e confronto político. Petrópolis, Vozes.

TILLY, Charles; TARROW, Sidney (2015), Contentious Politics. 2. ed. New York, Oxford University Press. 


\begin{abstract}
During the recent cycle of protests that happened between 2013 and 2016 in Brazil, a new theoretical and analytical attention was granted to organizational experiences, called collectives. This article, which is part of research in progress, aims at two goals: (i) assist in the detailed exam about the organizational experiences; (ii) conduct a discourse analysis of the identification process of the subjects as contemporary collectives. To contribute to the second aim, we will also use six interviews done with activists from cultural collectives in Vitoria, Espírito Santo, between December 2018 and March 2019. Considering the literature and our first research data, the structural argument of the analysis is that the building of the idea of collective also means the demarcation of a differential position related to other associative experiences.
\end{abstract}

Keywords: Collectives; differential position; new associative experiences; repertory.

\title{
Resumen
}

A partir del reciente ciclo de protestas que aconteció en Brasil entre 2013 y 2016, comenzó a darse una nueva atención teórico-analítica a las experiencias de organización social que se autodenominan colectivos. Con el propósito de contribuir a ese debate, este artículo - que es parte de una investigación en curso - se desarrolla en dos ejes: (i) el de la sistematización de elementos clave que se encuentran en la literatura reciente sobre colectivos, que podrían contribuir a un análisis más detallado sobre esas experiencias de organización social; y (ii) el de un análisis discursivo del proceso de identificación de los sujetos como colectivos contemporáneos. Como insumo para este segundo eje, nos valemos de seis entrevistas en profundidad realizadas a activistas de colectivos culturales de la ciudad de Victoria, Espíritu Santo, entre los meses de diciembre de 2018 y marzo de 2019. Tomando en cuenta los hallazgos de la literatura y nuestros primeros datos producidos en esta investigación, el argumento estructurador de este análisis es que la construcción de la idea de colectivo también significa la demarcación de una posición diferencial en relación con otras experiencias de organización social.

Palabras clave: Colectivos; posición diferencial; nuevas experiencias asociativas; repertorios. 